\title{
Reference Electrodes for Electrochemical Sensors Based on Redox Couples Immobilized within Nafion Films
}

\author{
Lifu Chen, Richard G Compton* \\ Department of Chemistry, Physical and Theoretical Chemistry Laboratory, Oxford University, South \\ Parks Road, Oxford OX1 3QZ, UK \\ *To whom correspondence should be addressed \\ Email: richard.compton@chem.ox.ac.uk
}

Phone: +44 (0) 1865275957

Fax: +44 (0) 1865275410

To be submitted to:

ACS Sensors 


\begin{abstract}
The immobilization of both components of a redox couple within films of the sulfonated tetrafluoroethylene polymer, Nafion, on the surface of carbon electrodes is reported. In particular cationic and/or water insoluble species are used to develop stable and robust reference electrodes by adjustment and optimization of both the film thickness and the level of doping of the film, as an alternative to standard commercial reference electrodes. Different redox couples were evaluated: methyl viologen dication/cation $\left(\mathrm{MV}^{2+} / \mathrm{MV}^{+}\right)$, tris $\left(2,2^{\prime}-\right.$ bipyridyl)ruthenium(II)/ruthenium(III) $\quad\left(\mathrm{Ru}(\mathrm{bpy}) 3_{3}{ }^{2+} / \mathrm{Ru}(\mathrm{bpy})_{3}{ }^{3+}\right), \quad$ ferrocene/ferrocenium $\left(\mathrm{Fc} / \mathrm{Fc}^{+}\right)$and poly(vinylferrocene)/poly(vinylferrocenium) $\left(\mathrm{PVFc} / \mathrm{PVFc}^{+}\right)$. These reference electrodes demonstrate good a stability over 10 days and 1000 successive scans; in particular Nafion confined $\mathrm{Fc} / \mathrm{Fc}^{+} \mathrm{PF}_{6}^{-}$was shown to display the best performance. This type of reference electrode, as a solid-state electrolyte-free reference electrode, has several advantages including full retention of the redox species within the films together with ease of both fabrication and miniaturization.
\end{abstract}

Keywords: Nafion Films, Solid-State Reference Electrodes, Electrochemical Sensors, Immobilization within Nafion Films, Miniaturization 
The reference electrode is an essential component of both potentiometric and amperometric experiments and the many chemical sensors - such as for $\mathrm{pH}$, for gases, for glucose, ......which depend on these types of measurement. The stability and robustness of the reference electrode often ultimately dictates the sensitivity and longevity of the sensor and hence its usefulness and range of applicability. Probably the most frequently made electrochemical sensing measurement is that of $\mathrm{pH}$ where since the pioneering work of Beckman in the 1920s, ${ }^{1,2}$ as in many other electrochemical sensors, the preferred reference electrode has been the silver/silver chloride electrode based on the half-cell reaction

$$
\mathrm{AgCl}(s)+e^{-} \rightleftarrows A g(s)+\mathrm{Cl}^{-}(a q)
$$

for which the Nernst equation is

$$
E=E^{0}-\frac{R T}{F} \ln a_{C l^{-}}
$$

where $\mathrm{E}$ and $\mathrm{E}^{0}$ are the electrode potential and standard electrode potential (and measured against a common reference electrode, conventionally a standard hydrogen electrode), $\mathrm{R}$ is the gas constant, $\mathrm{T}$ is the absolute temperature and $\mathrm{F}$ is the Faraday constant. The term $a_{c l^{-}}$is the activity of the chloride ion.

$$
a_{c l^{-}}=\gamma\left[C l^{-}\right]
$$

where $\gamma$ is the corresponding activity coefficient.

Equations (1)-(3) emphasize that a fixed chloride concentration is mandatory if a reproducible and stable electrode potential is to be established on the reference electrode. This is usually realized by bathing a $\mathrm{Ag} / \mathrm{AgCl}$ wire or foil in a solution of potassium chloride of a fixed molality, sometimes controlled by having solid $\mathrm{KCl}$ present to saturate the solution. 
At the same time it is essential to maintain some solid silver chloride at the surface of the silver electrode so as to sustain equilibrium (1). These two requirements can prove problematic in some applications particularly if the reference electrode is required to be miniaturized, as required for small volume measurements such as for use in scanning electrochemical microscopy (SECM) and scanning probe microscopy (SPM), or to be used in a flowing solutions since maintaining the presence of a zone of aqueous chloride solution close to the electrode adds to the size whilst exposure of the bare $\mathrm{Ag} / \mathrm{AgCl}$ electrode to chloride containing solution can result in the loss of $\mathrm{AgCl}$ from the surface, for example in the form of $\mathrm{AgCl}_{n}{ }^{(\mathrm{n}-1)-}$ complexes of which $\mathrm{AgCl}_{2}^{-}$is well-characterized. ${ }^{3,4}$ Thus the deployment of the $\mathrm{Ag} / \mathrm{AgCl} / \mathrm{Cl}^{-}$electrode or equally the closely related calomel electrode, $\mathrm{Hg} / \mathrm{Hg}_{2} \mathrm{Cl}_{2} / \mathrm{Cl}^{-}$is often challenging. This observation encourages the search for easier to use reference electrode systems which do not suffer from rapid deterioration of the response from loss of key chemical components in the potential-determining equilibrium (1).

In the following we consider an approach to the fabrication of reference electrode in which both components of a hydrophilic redox couple, $O x+e^{-} \rightleftarrows$ Red are immobilized within an ion exchange polymer. To do this, and building on the experience of ourselves ${ }^{5-7}$ and others $^{8-11}$ with the immobilization of cationic species within films and nanoparticles of Nafion, the well-known and widely applied sulfonated tetrafluoroethylene polymer. Specifically we evaluate the redox couples methyl viologen dication/cation $\left(\mathrm{MV}^{2+} / \mathrm{MV}^{+}\right)$, tris(2,2'-bipyridyl)ruthenium(II)/ruthenium(III) $\left(\operatorname{Ru}(\mathrm{bpy})_{3}{ }^{2+} / \mathrm{Ru}(\mathrm{bpy})_{3}{ }^{3+}\right)$, ferrocene/ferroceneium $\left(\mathrm{Fc} / \mathrm{Fc}^{+}\right)$and poly(vinylferrocene)/poly(vinylferrocenium) $\left(\mathrm{PVFc} / \mathrm{PVFc}^{+}\right)$within Nafion films. Note that in all the cases studied both components $(\mathrm{Ox}$ and $R e d$ ) of a redox couple are present and hence can be interconverted electrochemically, as exploited in the synthetic approach taken below, and are capable of establishing the 
$O x+e^{-} \rightleftarrows R e d$ equilibrium at the Nafion/electrode interface thus pinning the potential of the latter. The work is thus distinct from the use of a pair of redox reagents which are not complementary as a redox pair and hence cannot be interconverted electrochemically; the latter approach has been recently exploited in some all-solid-state ion-selective electrodes ${ }^{12,13}$

Nafion is selected as the host polymer since work has demonstrated ${ }^{14}$ that Nafion acts as a Donnan ion-exchange membrane in the presence of simple cations such as $\mathrm{Li}^{+}, \mathrm{Na}^{+}, \mathrm{K}^{+}, \mathrm{Ca}^{2+}$ and $\mathrm{Mg}^{2+}$ such that stable, rapidly formed $(<5 \mathrm{~s})$ potentials are established at the polymer/electrolyte solution interface. Reference electrodes as employed in voltammetric sensors are typically bathed by high ionic strength electrolyte ("background" or "supporting" electrolyte) which will thus provide a fixed potential at the polymer/solution interface which in combination with the fixed potential at the polymer/metal electrode will give a stable halfcell electrode signal. 


\section{Experimental}

\section{Chemical reagents}

All chemicals were used as received without further purification: ferrocenium hexafluorophosphate $\left(\mathrm{FcPF}_{6}, \geq 97 \%\right.$, Aldrich), methyl viologen dichloride $\left(\mathrm{MVCl}_{2}, \geq 98 \%\right.$, Aldrich), poly(vinylferrocene) (PVFc, molecular weight of $c a .50,000$, Polyscience Inc.), hexaammineruthenium(III) chloride $\left(\left[\mathrm{Ru}\left(\mathrm{NH}_{3}\right)_{6}\right] \mathrm{Cl}_{3}, \mathrm{Ru} \geq 32.1 \%\right.$, Alfa Aesar), tris(2,2'bipyridyl)dichlororuthenium(II) hexahydrate ( $\mathrm{Ru}(\mathrm{bpy}){ }_{3} \mathrm{Cl}_{2} \cdot 6 \mathrm{H}_{2} \mathrm{O}, \geq 99.95 \%$, Sigma-Aldrich), Nafion ${ }^{\circledR}$ perfluorinated resin solution $(5 \mathrm{wt} \%$ in lower aliphatic alcohol and water with a water content of $45 \%$, Sigma-Aldrich), potassium chloride ( $\mathrm{KCl}, \geq 99.0 \%$, Sigma-Aldrich), sodium chloride $\left(\mathrm{NaCl}, \geq 99.5 \%\right.$, Sigma-Aldrich), sodium phosphate dibasic $\left(\mathrm{Na}_{2} \mathrm{HPO}_{4}\right.$, $\geq 99.0 \%$, Sigma-Aldrich) and potassium phosphate monobasic $\left(\mathrm{KH}_{2} \mathrm{PO}_{4}, \geq 99.0 \%\right.$, SigmaAldrich). All solutions were prepared using ultrapure water (Millipore) with a resistivity of 18.2 $\mathrm{M} \Omega \mathrm{cm}$ at $298 \mathrm{~K}$ and degassed with Argon before use. Phosphate buffered saline buffer solution (PBS, $\mathrm{pH}=7.4$ ) was composed of $137.0 \mathrm{mM} \mathrm{NaCl}, 2.7 \mathrm{mM} \mathrm{KCl}, 10.0 \mathrm{mM}$ $\mathrm{Na}_{2} \mathrm{HPO}_{4}$ and $1.8 \mathrm{mM} \mathrm{KH}_{2} \mathrm{PO}_{4}$.

\section{Electrochemical Measurements}

Electrochemical experiments were performed using a $\mu$ Autolab Type II potentiostat (Utrecht, Netherlands) inside a grounded and thermostatted $\left(25.0 \pm 0.2{ }^{\circ} \mathrm{C}\right)$ Faraday cage. All measurements were conducted using standard three electrode setups employing different reference electrodes: saturated calomel electrode (SCE; BASi, Japan) or fabricated Nafion film reference electrodes. A glassy carbon (GC) macroelectrode (3.0 mm diameter of glassy carbon embedded into a solvent-resistant PCTFE plastic body, $\mathrm{CH}$ Instrument) and a graphite rod were used as working and counter electrodes respectively. 


\section{Fabrication of the Nafion film reference electrodes}

Four different reference electrodes were fabricated and studied in this work. These were based on the following redox couples, $\mathrm{MV}^{2+} / \mathrm{MV}^{+}, \mathrm{Ru}(\mathrm{bpy})_{3}{ }^{2+} / \mathrm{Ru}(\mathrm{bpy})_{3}{ }^{3+}, \mathrm{Fc}_{\mathrm{Fc}}{ }^{+}$and $\mathrm{PVFc} / \mathrm{PVFc}^{+}$immobilized in Nafion films. The fabrication of the $\mathrm{Fc} / \mathrm{Fc}^{+}$Nafion film reference electrode - the most successful electrode - is described in detail below. All other reference electrodes were fabricated in a similar way and details can be found in the Section 4 of the Supporting Information. The reference electrodes were optimised by adjusting the doping ratio (of redox couple to Nafion), the film thickness and the film morphology.

Preparation of the optimised $\mathrm{Fc} / \mathrm{Fc}^{+}$Nafion film reference electrode was carried out electrochemically. The $\mathrm{Fc}^{+} /$Nafion stock samples (with the doping ratio of $\mathrm{Fc}^{+}: \mathrm{SO}_{3}{ }^{-}=1: 30$ ) were prepared by directly dissolving $0.6 \mathrm{mg}$ of $\mathrm{Fc}^{+} \mathrm{PF}_{6}^{-}$into $1.30 \mathrm{~mL}$ Nafion perfluorinated resin solution. The mixture was shaken on a vortex (Whirlmixer, Loughborough, UK) for 5 min. $\mathrm{Fc}^{+} /$Nafion films were obtained by drop-casting $10 \mu \mathrm{L}$ of $\mathrm{Fc}^{+}$-Nafion solution on a bare glassy carbon (GC) macroelectrode and dried in a nitrogen environment at room temperature. Prior to use, the GC surface was cleaned by successively polishing with three grades of alumina (1.0, 0.3 and $0.05 \mu \mathrm{m}$, Buehler, UK) in a decreasing particle size order followed by sonication in water and drying with nitrogen. The $\mathrm{Fc} / \mathrm{Fc}^{+}$Nafion film reference electrode was then obtained electrochemically by sweeping the potential first cathodically from $0.5 \mathrm{~V}$ to $0.5 \mathrm{~V}$ vs. SCE then reversing back to $0.5 \mathrm{~V}$ at $0.1 \mathrm{~V} / \mathrm{s}$ for 20 repetitive scans in degassed $\mathrm{pH}$ 7.4 PBS buffer and, in the final scan, the potential stopping at $-0.005 \mathrm{~V}$, as shown in Figure $\mathrm{S} 1$. At this point, the $\mathrm{Fc}^{+}$was partially reduced and a Nafion film of $\mathrm{Fc} / \mathrm{Fc}^{+} \mathrm{PF}_{6}^{-}$was produced. The initial cycling is needed to stabilize the coating; the final partial scan injects a net charge so that both $\mathrm{Fc}$ and $\mathrm{Fc}^{+}$are present in the film. The relative amount of $\mathrm{Fc}$ and $\mathrm{Fc}^{+}$in Nafion films after the final scan is estimated to be $1: 548$ (See details in SI Section 5). The dry 
thickness of this film was estimated to be $35 \mu \mathrm{m}$ (See SI Section 3). The Nafion film prepared is uniform and homogeneous and its estimated thickness verified by AFM microscopy. ${ }^{15}$

\section{Characterization and stability study of Nafion film reference electrodes}

The stability of the Nafion film references electrodes was assessed voltammetrically in aqueous solutions with $\left[\mathrm{Ru}\left(\mathrm{NH}_{3}\right)_{6}\right] \mathrm{Cl}_{3}$ as an redox indicator using cyclic voltammetry. $\left[\mathrm{Ru}\left(\mathrm{NH}_{3}\right)_{6}\right]^{3+} /\left[\mathrm{Ru}\left(\mathrm{NH}_{3}\right)_{6}\right]^{2+}$ was chosen as the redox couple because the reduction of $\mathrm{Ru}\left(\mathrm{NH}_{3}\right)_{6}{ }^{3+}$ is fully reversible and well-characterized. ${ }^{16}$ Cyclic voltammetry of $1.0 \mathrm{mM}$ $\left[\mathrm{Ru}\left(\mathrm{NH}_{3}\right)_{6}\right] \mathrm{Cl}_{3}$ in the presence of $0.1 \mathrm{M} \mathrm{KCl}$ supporting electrolyte was performed at a $\mathrm{GC}$ macroelectrode as working electrode with the fabricated reference electrode and a graphite counter electrode at $0.1 \mathrm{~V} \mathrm{~s}^{-1}$ and the peak potentials of the voltammograms were monitored to give an indication of any drift or instability of the reference electrodes. Note that the presence of the fixed concentration of $0.1 \mathrm{M} \mathrm{KCl}$ ensures that there is a stable, constant potential at the polymer/electrolyte 'interface' arising from the Nafion acting as a Donnan exclusion membrane as discussed above. ${ }^{14}$ 


\section{Results and discussion}

Three main parameters of the films, namely doping ratio, film thickness and morphology were investigated to optimise the performance and stability for all four Nafion film reference electrodes. The stability and robustness of the $\mathrm{Fc}_{\mathrm{Fc}}{ }^{+}$Nafion film reference electrodes fabricated under optimized conditions are shown to be optimal amongst the different systems investigated.

\section{Electrode performance optimisation}

Studies on a series of redox couples doped in Nafion film reference electrodes are reported below. In particular, we first studied the electrochemistry of $\mathrm{MV}^{2+} / \mathrm{MV}^{+}$and $\mathrm{Ru}(\mathrm{bpy})_{3}{ }^{2+} / \mathrm{Ru}(\mathrm{bpy})_{3}{ }^{3+}$ doped in Nafion, since both cations of the couples are reported to have strong affinity with $\mathrm{SO}_{3}{ }^{-}$group of Nafion. ${ }^{5,6}$ The ion transport behaviour in Nafion film was then investigated experimentally and theoretically, ${ }^{7}$ and both cations were proved to fully be confined within both thin and thick Nafion films. Consequently at least in principle they can be applied as reference electrodes showing a good stability. The fabrication procedure of $\mathrm{MV}^{2+} / \mathrm{MV}^{+}$and $\mathrm{Ru}(\mathrm{bpy}){ }_{3}{ }^{2+} / \mathrm{Ru}(\mathrm{bpy})_{3}{ }^{3+}$ Nafion film reference electrodes was similar to that of $\mathrm{Fc} / \mathrm{Fc}^{+}$as described above and full details can be found in the SI Section 4. In the following the reversible one-electron transfer redox couple of $\left[\mathrm{Ru}\left(\mathrm{NH}_{3}\right)_{6}\right]^{3+} /\left[\mathrm{Ru}\left(\mathrm{NH}_{3}\right)_{6}\right]^{2+}$ is used to determine the potential of Nafion film reference electrodes and their stability. In essence a cyclic voltammogram of $\left[\mathrm{Ru}\left(\mathrm{NH}_{3}\right)_{6}\right]^{3+}$ in fully supported aqueous media at a carbon working electrode is recorded using the candidate reference electrodes as the reference electrode in a conventional three-electrode voltammetric measurement. Any change in the potential of the $\mathrm{Ru}(\mathrm{III}) / \mathrm{Ru}(\mathrm{II})$ couple is used to infer changes of potential in the reference electrode. Two important parameters of the film, namely doping ratio (initial doped species : $\mathrm{SO}_{3}{ }^{-}$) and 
thickness of the film, were initially investigated to optimise the performance and stability of the reference electrodes.

\section{Effect of doping ratio}

Five $\mathrm{MV}^{2+} / \mathrm{MV}^{+}$Nafion films with same thickness $(0.35 \mu \mathrm{m})$ but different initial doping ratios (the ratio of $\mathrm{MV}^{2+}: \mathrm{SO}_{3}{ }^{-}$) were fabricated. Note that the relative amount of $\mathrm{MV}^{+}$and $\mathrm{MV}^{2+}$ within Nafion film after fabrication is estimated as $1: 133$ (See SI Section S5 for details). Figure S2 shows a typical cyclic voltammogram (CV) of hexaammineruthenium(III) chloride recorded on a $\mathrm{GC}$ electrode with a freshly fabricated $\mathrm{MV}^{2+} / \mathrm{MV}^{+}$Nafion film reference electrode (with the initial doping ratio of $\mathrm{MV}^{2+}: \mathrm{SO}_{3}{ }^{-}=1: 30$ ) and graphite counter electrode in a solution containing $1 \mathrm{mM}\left[\mathrm{Ru}\left(\mathrm{NH}_{3}\right)_{6}\right] \mathrm{Cl}_{3}$ supported with $0.1 \mathrm{M} \mathrm{KCl}$. The midpoint potential ( $\mathrm{E}_{\mathrm{mid}}$; taken as the average of the cathodic and anodic peak potentials) of the mediator was $-0.165 \mathrm{~V}$ vs. $\mathrm{MV}^{2+} / \mathrm{MV}^{+}$Nafion film. The $\mathrm{CVs}$ of $\left[\mathrm{Ru}\left(\mathrm{NH}_{3}\right)_{6}\right]^{3+}$ were recorded over three hours after the electrode was immersed in the solution, and the $\mathrm{E}_{\mathrm{mid}}$ was determined and plotted as a function of time, as shown in Figure 1. At a very high initial doping ratio $\left(\mathrm{MV}^{2+}: \mathrm{SO}_{3}{ }^{-}=1: 4\right)$, the potential of the $\mathrm{MV}^{2+} / \mathrm{MV}^{+}$Nafion films drifts $($ca. 51 $\mathrm{mV}$ from the stabilized potential) in the first $10 \mathrm{~min}$ before it stabilize. This might reflect the depletion of doped redox species in the film when the doping ratio is too high and the level of $\mathrm{SO}_{3}{ }^{-}$in Nafion is insufficient to retain the excess dopant chemicals. For doping ratios ranging from $1: 30$ to $1: 100$, a very stable potential with a deviation less than $0.5 \mathrm{mV}$ of the thin Nafion film electrodes over two hours was obtained. This is consistent with our previous study ${ }^{6,7}$, where excess $\mathrm{MV}^{2+}$ was used to dope Nafion and the final product after washing gives a stable doping ratio of $1: 20$, suggesting this is the maximum stable uptake limit. For the films with a doping ratio of $1: 200$, a fluctuating $E_{\text {mid }}$ potential $( \pm 4 \mathrm{mV})$ was observed. This might result from an inhomogeneous distribution of the redox species, $\mathrm{MV}^{2+}$ and $\mathrm{MV}^{+}$, 
within the Nafion film at extreme low doping ratios. A doping ratio (initial doped species : $\mathrm{SO}_{3}{ }^{-}$) of $1: 30$ was chosen for the subsequent study in this work.

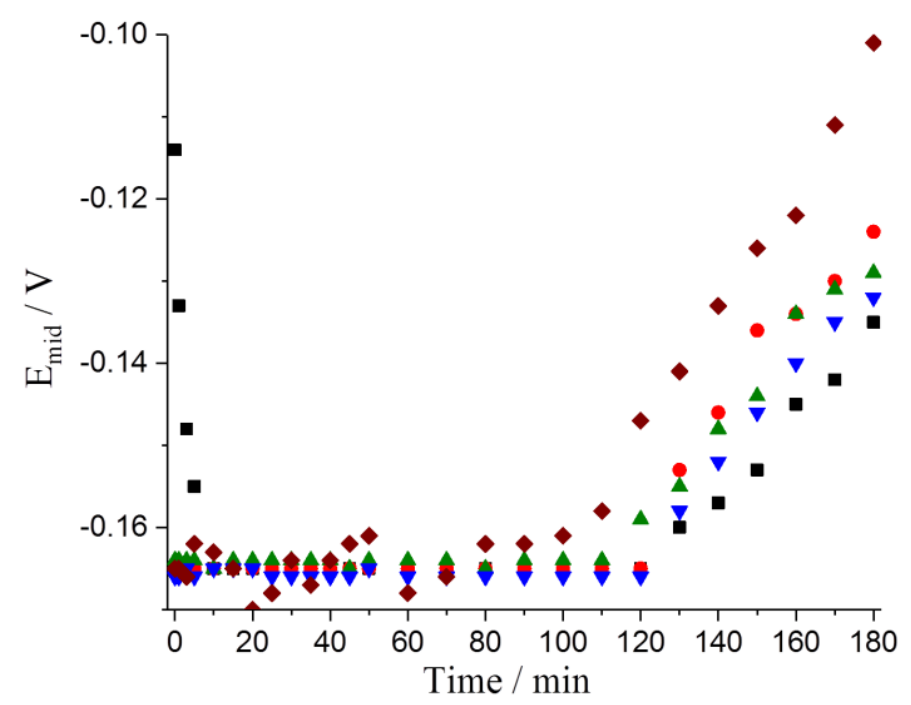

Figure 1. The midpoint potential, $\mathrm{E}_{\text {mid }}$, of $\left[\mathrm{Ru}\left(\mathrm{NH}_{3}\right)_{6}\right]^{3+}$ reduction $v s . \mathrm{MV}^{2+} / \mathrm{MV}^{+}$Nafion film (with the film thickness of $0.35 \mu \mathrm{m}$ ) reference electrodes with different doping ratios recorded over three hours (doping ratio $=1: 4$, black dot; doping ratio $=1: 30$, red dot; doping ratio = $1: 50$, blue dot; doping ratio $=1: 100$, green dot; doping ratio $=1: 200$, brown dot).

Another important observation was that for all five different Nafion films reference electrodes of thickness $0.35 \mu \mathrm{m}$, the potential started to drift after $c a .120 \mathrm{~min}$ in the solution (35 $\pm 3 \mathrm{mV} / \mathrm{h})$. This suggests that the Nafion films at this thickness $(0.35 \mu \mathrm{m})$ have $c a$. two hour lifetime in aqueous solution before degradation. Nafion film reference electrodes with different thickness were then investigated to achieve a longer lifetime and better stability.

\section{Effect of film thickness}

In a similar way to the above, we investigated the stability of Nafion film reference electrodes with different film thicknesses by examining via $\mathrm{CV}$ the potential for the $\left[\mathrm{Ru}\left(\mathrm{NH}_{3}\right)_{6}\right]^{3+}$ reduction in aqueous solution. As depicted in Figure $2 \mathrm{a}$, the $\mathrm{E}_{\text {mid }}$ potential of the $\mathrm{Ru}(\mathrm{III}) / \mathrm{Ru}(\mathrm{II})$ couple using five $\mathrm{MV}^{2+} / \mathrm{MV}^{+}$Nafion film reference electrodes at a same initial doping ratio $\left(\mathrm{MV}^{2+}: \mathrm{SO}_{3}^{-}=1: 30\right)$ but with different film thickness was recorded over 6 hours. The $\mathrm{E}_{\mathrm{mid}}$ 
potential of the couple measured with films with $0.35 \mu \mathrm{m}$ and $1.75 \mu \mathrm{m}$ thickness is stable (fluctuating within $1 \mathrm{mV}$ ) for 2 hours and 4.5 hours respectively before it starts to drift (30 \pm $3 \mathrm{mV} / \mathrm{h}$ ) whilst the potential of the three thicker films does not drift at all within 6 hours, suggesting an enhanced stability of the Nafion film reference electrodes in aqueous solution with a thicker film thickness. The drift in potential of the Nafion films with film thickness of $0.35 \mu \mathrm{m}$ and $1.75 \mu \mathrm{m}$ after 2 to 5 hours was most likely due to a relatively fast chemical or mechanical degradation or aging of the very thin Nafion films. ${ }^{17}$, 18 The Nafion films/membranes prepared by dropcasting with thicknesses ranging from 25 to $50 \mu \mathrm{m}$ have been reported as thin enough to withstand the aggressive chemical and environmental conditions while meeting the durability targets for commercialization and have been extensively investigated over the past decade. ${ }^{19-21}$ Reinforced Nafion films can approach 5 $\mu \mathrm{m}$ in thickness without significantly compromising the stability. ${ }^{22}$ This consistent with our observation as the three thicker films have little potential fluctuation $( \pm 0.5 \mathrm{mV})$ in the whole 6-hour measurements and good stability.
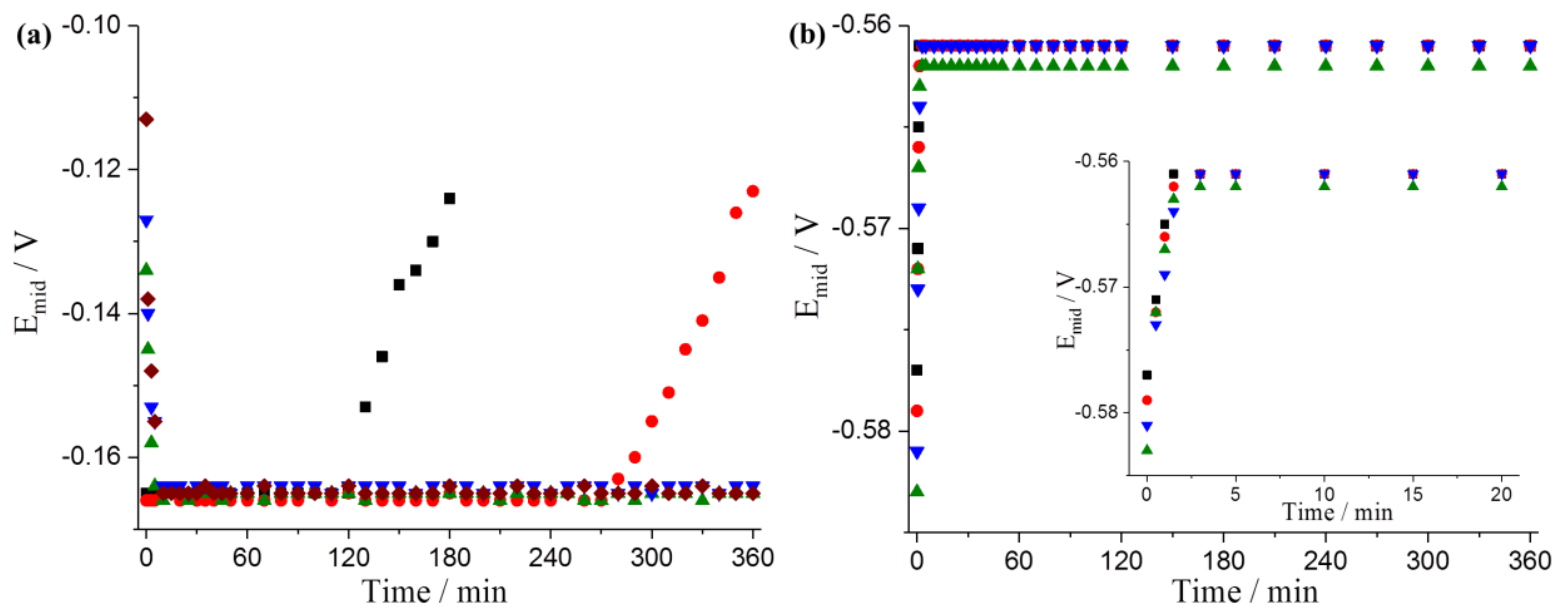

Figure 2. (a) The midpoint potential, $\mathrm{E}_{\text {mid }}$, of $\left[\mathrm{Ru}\left(\mathrm{NH}_{3}\right)_{6}\right]^{3+}$ reduction $v s . \mathrm{MV}^{2+} / \mathrm{MV}^{+}$Nafion film (with a doping ratio of $1: 30$ ) reference electrodes with different film thickness recorded over six hours $(0.35 \mu \mathrm{m}$ film thickness, black dot; $1.75 \mu \mathrm{m}$ film thickness, red dot; $7.0 \mu \mathrm{m}$ film thickness, blue dot; $17.5 \mu \mathrm{m}$ film thickness, green dot; $35 \mu \mathrm{m}$ film thickness, brown dot). (b) $\mathrm{E}_{\text {mid }}$ of $\left[\mathrm{Ru}\left(\mathrm{NH}_{3}\right)_{6}\right]^{3+}$ reduction $v$ s. $\mathrm{Ru}(\mathrm{bpy})_{3}{ }^{2+} / \mathrm{Ru}(\mathrm{bpy})_{3}{ }^{3+}$ Nafion film (with a doping ratio of 1 : 30) reference electrodes with different film thickness recorded over six hours $(7.0 \mu \mathrm{m}$ film thickness, black dot; $17.5 \mu \mathrm{m}$ film thickness, red dot; $35 \mu \mathrm{m}$ film thickness, blue dot; $52.6 \mu \mathrm{m}$ film thickness, green dot). Inset is the zoom-in of first $20 \mathrm{~min}$. 
Four Ru(bpy $)_{3}{ }^{2+} / \mathrm{Ru}(\mathrm{bpy})_{3}{ }^{3+}$ Nafion film reference electrodes with a doping ratio of $1: 30$ and a thick film thickness (from 7.0 to $52.6 \mu \mathrm{m}$ ) were fabricated and examined. The relative amount of $\mathrm{Ru}(\mathrm{bpy})_{3}{ }^{2+}$ and $\mathrm{Ru}(\mathrm{bpy})_{3}{ }^{3+}$ in Nafion films is estimated to be $1: 174$ (SI Section 5). As shown in Figure 2b, all four Nafion film electrodes exhibit a good stability with less than $0.5 \mathrm{mV}$ deviation over six hours, consistent with the observation of $\mathrm{MV}^{2+} / \mathrm{MV}^{+}$Nafion films, indicating Nafion films thicker than $7 \mu \mathrm{m}$ have at least 6 hours lifetime and good stability in aqueous solution.

We also noticed that there was an initial potential drift within first a few minutes after fabrication for three thicker $\mathrm{MV}^{2+} / \mathrm{MV}^{+}$Nafion film $(7.0$ to $35 \mu \mathrm{m})$ and all the four $\mathrm{Ru}(\mathrm{bpy})_{3}{ }^{2+} / \mathrm{Ru}(\mathrm{bpy})_{3}{ }^{3+}$ Nafion film $(7.0$ to $52.6 \mu \mathrm{m})$ reference electrodes before the potential was stable with less than $0.5 \mathrm{mV}$ drift for at least the next 6 hours. A larger initial potential drift and a longer drift time were also observed for the thickest film (ca. $52 \mathrm{mV}$ initial potential drift within $5 \mathrm{~min}$ for $35 \mu \mathrm{m} \mathrm{MV} \mathrm{MV}^{2+} / \mathrm{MV}^{+}$film whilst $31 \mathrm{mV}$ drift within $1.5 \mathrm{~min}$ for $7 \mu \mathrm{m}$ film in Figure 2a). The previous section has discussed that both cations are fully confined inside Nafion at this doping ratio hence this potential drift does not result from depletion of doped redox species. We inferred that this initial potential deviation was most likely due to the redistribution of the redox couples via diffusion within the Nafion films during/after fabrication process. This may be driven by concentration gradients or/and charge gradients within the thicker Nafion films (several microns or above) as $\mathrm{MV}^{+}$or $\mathrm{Ru}(\mathrm{bpy})_{3}{ }^{2+}$ is only generated in the film near the electrode surface during the electrochemical oxidation/reduction of the film in its preparation leading to the concentration and charge gradients across the films consequently the diffusion of both redox species inside the films, as illustrated in Scheme 1. This is also consistent with the fact that a thicker film requires a longer initial potential drift time to obtain a homogenous distribution within the film and hence a stable potential. 

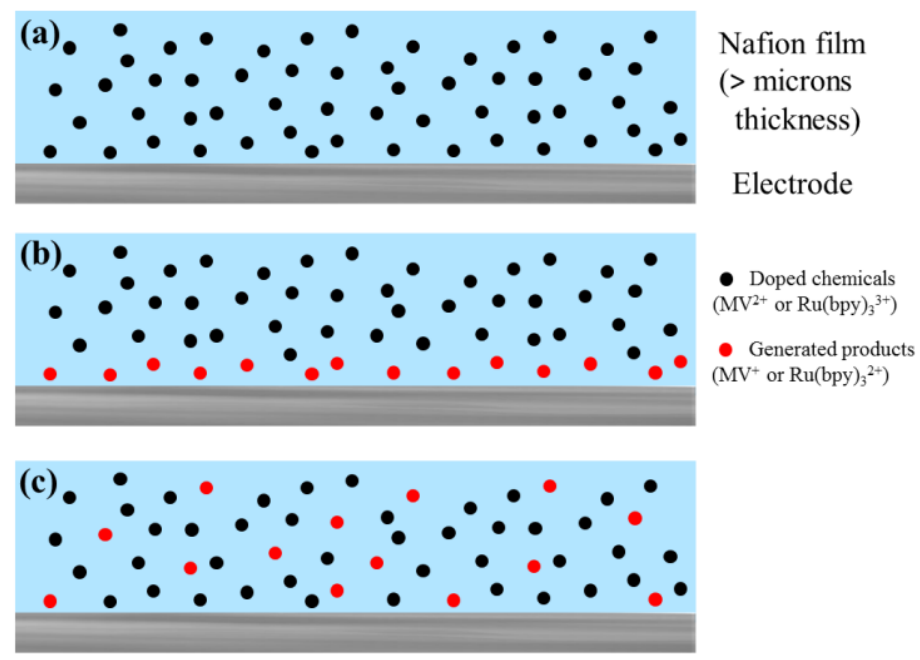

Nafion film

(> microns

thickness)

Electrode

Doped chemical

Generated product $\left(\mathrm{MV}^{+}\right.$or $\left.\mathrm{Ru}(\mathrm{bpy})_{3}{ }^{2+}\right)$

Scheme 1. Illustration of initial potential drift of the Nafion films (a) fresh prepared Nafion films via dropcasting: the doped chemicals $\left(\mathrm{MV}^{2+}\right.$ or $\left.\mathrm{Ru}(\mathrm{bpy})_{3}{ }^{2+}\right)$ are homogeneous within the film. (b) the films during electrochemically fabrication: generated products $\left(\mathrm{MV}^{+}\right.$or $\left.\mathrm{Ru}(\mathrm{bpy})_{3}{ }^{3+}\right)$ are formed in the film near the electrode surface side leading concentration and charge gradients within the film consequently causing the initial potential drift. (c) after a few minutes the redox couples are homogeneous within the films via diffusion and the potential of the films are stabilized.

Previously, we have systematically investigated and compared the diffusional transport of $\mathrm{MV}^{2+}$ and $\mathrm{MV}^{+}$in Nafion films and particles, and found that the transport in the particles was significantly faster than in films of similar thickness. ${ }^{7}$ This observation suggest an experiment conducted using MV doped Nafion particles to fabricate $\mathrm{MV}^{2+} / \mathrm{MV}^{+}$Nafion particle based reference electrodes (fabrication details see SI Section 6). As depicted in Figure S3, the initial potential stabilization of $\mathrm{MV}^{2+} / \mathrm{MV}^{+}$Nafion particles reference electrode was completed much faster than that of Nafion films of similar thickness (ca. $45 \mathrm{mV}$ drift within $1.5 \mathrm{~min}$ for $38.7 \mu \mathrm{m}$ particle layers vs. $52 \mathrm{mV}$ drift within $5 \mathrm{~min}$ for $35.1 \mu \mathrm{m}$ film), consistent with the faster diffusional transport of both cations inside the particles consequently a short stabilization time for a homogeneous distribution in Nafion.

Another important question arises namely which part, the generated product during fabrication or the initial doped reactant, predominantly causes this initial potential drift. We 
speculate that the product more likely has a significant effect, as it is only generated in the film near the electrode surface side and needs to diffuse cross over the whole film to reach homogeneous state whilst the doped reactant is more like 'bulk' species within the entire film. The diffusion coefficient of $\mathrm{MV}^{2+}$ and $\mathrm{MV}^{+}$within a Nafion film of several micron thickness has been reported previously as $3 \times 10^{-9} \mathrm{~cm}^{2} \mathrm{~s}^{-1}$ and $3 \times 10^{-10} \mathrm{~cm}^{2} \mathrm{~s}^{-1}$ whilst the diffusion coefficient of $\mathrm{Ru}(\mathrm{bpy})_{3}{ }^{3+}$ and $\mathrm{Ru}(\mathrm{bpy})_{3}{ }^{2+}$ in Nafion film is $1.2 \times 10^{-9} \mathrm{~cm}^{2} \mathrm{~s}^{-1}$ and $2.7 \times 10^{-9}$ $\mathrm{cm}^{2} \mathrm{~s}^{-1}$ respectively. ${ }^{7,8,23}$ The $\mathrm{Ru}(\mathrm{bpy})_{3}{ }^{2+} / \mathrm{Ru}(\mathrm{bpy})_{3}{ }^{3+}$ Nafion films exhibit a faster initial potential stabilization compared with $\mathrm{MV}^{2+} / \mathrm{MV}^{+}$Nafion films at a same doping ratio and film thickness in Figure 2, suggesting the inhomogeneous distribution of generated product $\left(\mathrm{Ru}(\mathrm{bpy})_{3}{ }^{2+}\right.$ and $\mathrm{MV}^{+}$) during the fabrication for a thick film is predominant to cause observed initial potential drift as $\mathrm{Ru}(\mathrm{bpy})_{3}{ }^{2+}$ diffuses faster than $\mathrm{MV}^{+}$in Nafion film whereas $\mathrm{Ru}(\mathrm{bpy}) 3^{3+}$ diffuses slower than $\mathrm{MV}^{2+}$. This hypothesis is further investigated in the next section.

In subsequent studies, we chose a film thickness of $35 \mu \mathrm{m}$ as films of this thickness demonstrated a good stability without significantly compromising their performance once the initial potential drift is stabilized within $c a .5$ minutes. The influence of morphology of the film on this process was then investigated. 


\section{Effect of film morphology}

The morphology of a Nafion film itself is an extremely complicated topic as has been reviewed. ${ }^{24-26}$ In this work, we qualitatively investigated how morphology might affect the performance and stability of the film. The Nafion films prepared via dropcasting has been proved to be uniform and homogeneous and its estimated thickness is accurate, as verified by AFM microscopy. ${ }^{15}$ In order to obtain a film with higher roughness but similar thickness, the same amount of Nafion stock mixture was dropcasted on electrode surface not once but casting five times the same overall amount of material (as detailed in the SI). In this way, a film with an obvious surface roughness as judged microscopically was obtained, as shown in Figure S4.

Both $\mathrm{MV}^{2+} / \mathrm{MV}^{+}$and $\mathrm{Ru}(\mathrm{bpy}){ }_{3}{ }^{2+} / \mathrm{Ru}(\mathrm{bpy}){ }_{3}{ }^{3+}$ Nafion film reference electrodes with high film surface roughness were fabricated and examined. The $\mathrm{E}_{\text {mid }}$ potential was recorded and compared with that of uniform films as shown in Figure 3. A large initial potential deviation from the ultimate stable reading and a much longer stabilisation time for rough films were observed in both cases. This is consistent with the insight that the homogenization of generated $\mathrm{MV}^{+}$or $\mathrm{Ru}(\mathrm{bpy})_{3}{ }^{2+}$ within an nonuniform film is probably diffusionally more difficult and requires a longer time, and consequently a stable potential is achieved more slowly. We then tested the potentials of both uniform and rough films over three days after their stabilization with the same film electrode after washing with water and kept in air without any protection, as depicted in Figure S5. There was no significant difference. These results suggest that the morphology of Nafion films has a significant effect on initial performance (an initial potential drift) of the reference electrode but plays a negligible role in terms of stability. 

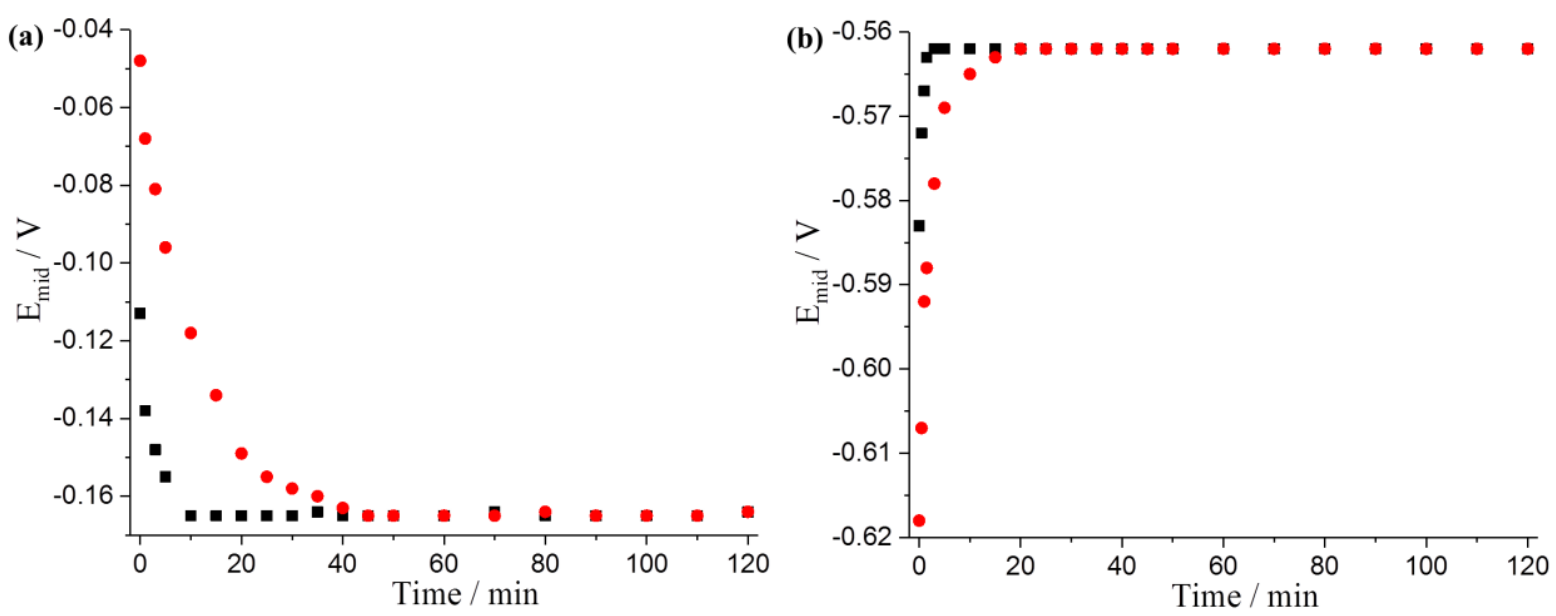

Figure 3. (a) The midpoint potential, $\mathrm{E}_{\text {mid }}$, of $\left[\mathrm{Ru}\left(\mathrm{NH}_{3}\right)_{6}\right]^{3+}$ reduction $v$ s. $\mathrm{MV}^{2+} / \mathrm{MV}^{+}$Nafion film (with a doping ratio of $1: 30$ and film thickness of $35.1 \mu \mathrm{m}$ ) reference recorded over two hours (uniform film surface, black dot; rough film surface, red dot). (b) $E_{\text {mid }}$ of $\left.\left[\mathrm{Ru}_{(\mathrm{NH}}\right)_{6}\right]^{3+}$ reduction $v$ s. $\mathrm{Ru}(\mathrm{bpy})_{3}{ }^{2+} / \mathrm{Ru}(\mathrm{bpy})_{3}{ }^{3+}$ Nafion film (with a doping ratio of $1: 30$ and film thickness of $35.1 \mu \mathrm{m}$ ) reference electrodes recorded over two hours (uniform film surface, black dot; rough film surface, red dot).

We next considered if the initial potential drift of fresh fabricated films could be mitigated or fully eliminated. In the previous section, we inferred this drift was due to inhomogeneous distribution of generated product within the films during the fabrication process. To examine this hypothesis, two more types of Nafion film reference electrodes, $\mathrm{Fc} / \mathrm{Fc}^{+}$and $\mathrm{PVFc} / \mathrm{PVFc}^{+}$, were fabricated and examined. These two couples were chosen as Fc and PVFc are insoluble in water.

To prepare $\mathrm{Fc} / \mathrm{Fc}^{+}$Nafion film reference electrodes (initial doping ratio of $\mathrm{Fc}^{+}: \mathrm{SO}_{3}{ }^{-}=1: 30$ and thickness of $35 \mu \mathrm{m}$ ), the soluble salt, $\mathrm{Fc}^{+} \mathrm{PF}_{6}^{-}$, was initially doped into Nafion and insoluble Fc was generated via partial electro-reduction of the film as described above. The $\mathrm{Fc} / \mathrm{Fc}^{+}$Nafion film reference electrodes demonstrated a superior stability without any initial drift, as shown in Figure S6 and discussed in detail in next section. The initial potential drift was successfully and fully eliminated, suggesting the above hypothesis maybe correct namely that an inhomogeneous distribution of the generated product within the film plays a 
predominant role to cause an initial potential drift and this drift could be fully eliminated if the product is water-insoluble. Another $\mathrm{Fc} / \mathrm{Fc}^{+}$Nafion film reference electrode with a high surface roughness was fabricated and examined. As shown in Figure S7, the film exhibited same stability without any initial potential drift showing insensitivity to morphology further confirming the hypothesis.

$\mathrm{PVFc} / \mathrm{PVFc}^{+}$Nafion film reference electrodes (initial doping ratio of $\mathrm{VFc}$ moiety $: \mathrm{SO}_{3}{ }^{-}=1$ : 30, thickness of $35 \mu \mathrm{m}$ and the relative amount of $\mathrm{PVFc}^{+}$and $\mathrm{PVFc}$ in Nafion films is $1: 903$ ) were fabricated in a contrast way to the $\mathrm{Fc} / \mathrm{Fc}^{+}$Nafion film where the insoluble PVFc was initially doped into Nafion but water-soluble $\mathrm{PVFc}^{+}$was electrochemically generated. The film reference electrodes were examined as a function of time, as depicted Figure S8, showing a good stability with less than $0.5 \mathrm{mV}$ deviation over one hour but with an initial potential drift (ca. $15 \mathrm{mV}$ ) at first 15 minutes suggesting the homogenization of the freshly generated $\mathrm{PVFc}^{+}$within the film. This observation is consistent with that of $\mathrm{MV}^{2+} / \mathrm{MV}^{+}$and $\mathrm{Ru}(\mathrm{bpy})_{3}{ }^{2+} / \mathrm{Ru}(\mathrm{bpy})_{3}{ }^{3+}$, confirming again the hypothesis.

All four types of Nafion film reference electrode under optimized conditions (doping ratio of $1: 30$, film thickness of $35 \mu \mathrm{m}$ and uniform film surface) were examined. The performance of the system $\mathrm{Fc} / \mathrm{Fc}^{+}$Nafion film reference electrode is demonstrated in detail below, others are described in the SI Section 2 and Figure S11-S13.

\section{Stability of the $\mathrm{Fc} / \mathrm{Fc}^{+}$Nafion film reference electrodes}

The potential of optimized $\mathrm{Fc} / \mathrm{Fc}^{+}$Nafion film reference electrodes and their stability were also assessed voltammetrically. Figure 4a black line shows a CV of reduction of $\left[\mathrm{Ru}\left(\mathrm{NH}_{3}\right)_{6}\right]^{3+}$ against a freshly fabricated $\mathrm{Fc} / \mathrm{Fc}^{+}$Nafion film reference electrode. The 
midpoint potential, $\mathrm{E}_{\mathrm{mid}}$, of the mediator was $-0.235 \mathrm{~V} v$ s. $\mathrm{Fc} / \mathrm{Fc}^{+}$Nafion film. The $\mathrm{E}_{\mathrm{mid}}$ of reduction of $\left[\mathrm{Ru}\left(\mathrm{NH}_{3}\right)_{6}\right]^{3+}$ vs. SCE is $-0.176 \mathrm{~V}$, as shown in Figure S9. Therefore, the potential of fabricated $\mathrm{Fc} / \mathrm{Fc}^{+}$Nafion film reference electrode in aqueous solution was determined as $-0.059 \mathrm{~V} v s$. SCE or $+0.182 \mathrm{~V}$ vs. NHE, as illustrated in Scheme 2.
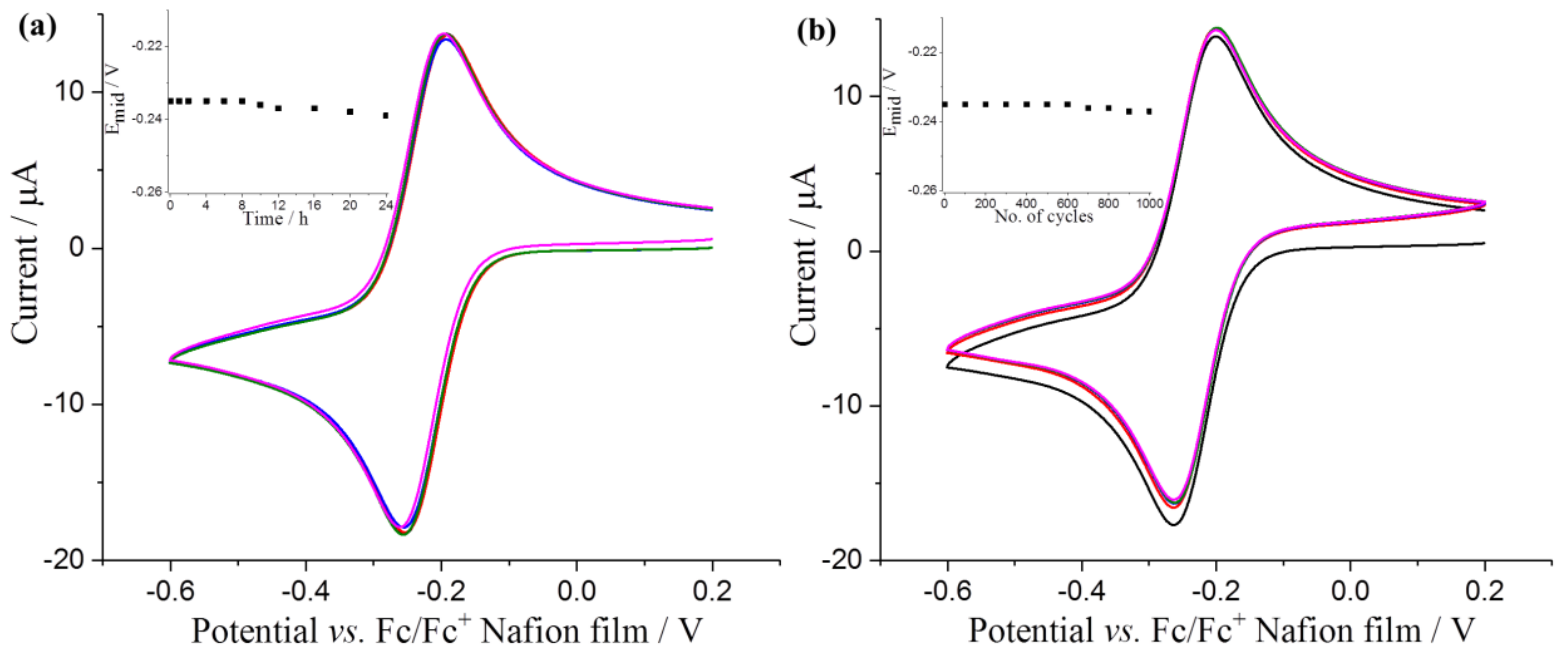

Figure 4. (a) Voltammograms of a glassy carbon working electrode with a $\mathrm{Fc} / \mathrm{Fc}^{+}$Nafion film reference electrode in $0.1 \mathrm{M} \mathrm{KCl}$ aqueous solution containing $1 \mathrm{mM}\left[\mathrm{Ru}\left(\mathrm{NH}_{3}\right)_{6}\right] \mathrm{Cl}_{3}$ at a scan rate of $0.1 \mathrm{~V} \mathrm{~s}^{-1}$ recorded after the electrodes immersing in solution (fresh, black line; $2 \mathrm{~h}$, red line; $6 \mathrm{~h}$, blue; $12 \mathrm{~h}$, green line; $24 \mathrm{~h}$, magenta line). Inset shows the midpoint potential, $\mathrm{E}_{\text {mid }}$, over the time. (b) Voltammograms recorded over 1000 successive scans $\left(1^{\text {st }}\right.$ scan, black line; $100^{\text {th }}$ scan, red line; $200^{\text {th }}$ scan, blue; $600^{\text {th }}$ scan, green line; $1000^{\text {th }}$ scan, magenta line). Inset shows the midpoint potential, $\mathrm{E}_{\mathrm{mid}}$, over the number of scans. Raw data of the insets has been tableted in Table S1\&2.

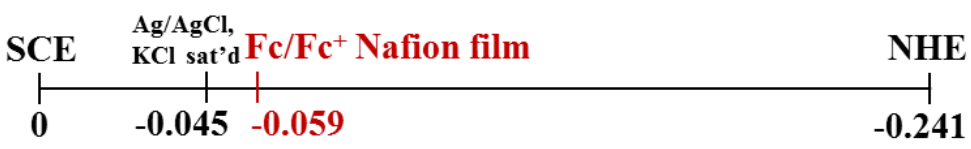

Scheme 2. The potential of $\mathrm{Fc} / \mathrm{Fc}^{+}$Nafion film reference electrode in aqueous solution

As shown in Figure 4a, the CVs of $\left[\mathrm{Ru}\left(\mathrm{NH}_{3}\right)_{6}\right]^{3+}$ were recorded over a 24-h period after the electrodes had remained in the cell under the same conditions to check the stability of the $\mathrm{Fc} / \mathrm{Fc}^{+}$Nafion film reference electrode. The peak potentials were very stable with no deviation for the first 6 hours after the $\mathrm{Fc} / \mathrm{Fc}^{+}$Nafion film was immersed in the solution. The 
variation of $E_{\text {mid }}$ with experimental time was within an average deviation of $2 \mathrm{mV}$ over 12 hours and less than $5 \mathrm{mV}$ after 24 hours in solution. Moreover, additional voltammograms were recorded every one or two days over a period of 10 days, with the same $\mathrm{Fc} / \mathrm{Fc}^{+}$Nafion film electrode after washing with water and kept in air without any protection, as shown in Figure S10. This shows again a good stability of the $\mathrm{Fc} / \mathrm{Fc}^{+}$film with no significant drift of the $\mathrm{E}_{\mathrm{mid}}$ within $10 \mathrm{mV}$ over 10 days and less than $0.5 \mathrm{mV}$ deviation in the first 4 days. Moreover, there was no visible degradation of the film over 10 days. There results clearly demonstrate the high stability and strong robustness of $\mathrm{Fc} / \mathrm{Fc}^{+}$Nafion film used as reference electrode in aqueous solution.

To test the stability of the $\mathrm{Fc} / \mathrm{Fc}^{+}$Nafion film after a series of measurements, the cyclic voltammetry was conducted over 1000 successive scans in the same conditions with a fresh fabricated $\mathrm{Fc} / \mathrm{Fc}^{+}$Nafion film reference electrode. As shown in Figure 4b, there was no drift of the peak potential or $\mathrm{E}_{\text {mid }}$ between the first and $600^{\text {th }}$ cycle and only $2 \mathrm{mV}$ drift after 1000 cycles, demonstrating a superior stability of the $\mathrm{Fc} / \mathrm{Fc}^{+}$Nafion films.

\section{Reproducibility of the $\mathrm{Fc} / \mathrm{Fc}^{+}$Nafion films}

The above results reveal a highly stable $\mathrm{Fc} / \mathrm{Fc}^{+}$Nafion film reference electrode. An important question arises as to the reproducibility of this film electrode. Three $\mathrm{Fc}^{+} / \mathrm{Nafion}$ stock samples were prepared and used to dropcast on three different glassy carbon electrodes. Cyclic voltammetry of $1.0 \mathrm{mM}\left[\mathrm{Ru}\left(\mathrm{NH}_{3}\right)_{6}\right]^{3+}$ (in $0.1 \mathrm{M} \mathrm{KCl}$ ) at the scan rate of $0.1 \mathrm{mV} \mathrm{s}{ }^{-1}$ was recorded to examined each film reference electrodes. The midpoint potential, $\mathrm{E}_{\mathrm{mid}}$, remained at $-0.235 \pm 0.002 \mathrm{~V}$ vs. $\mathrm{Fc}_{\mathrm{Fc}}{ }^{+}$Nafion film in all cases, showing excellent reproducibility of the electrodes; see Table S3\&4 for raw data.

We now have fabricated four different Nafion film references electrodes with good stability over 10 days and performed over at least 1000 successive scans. That said the performance 
and the durability of this type of Nafion film reference electrodes might be further improved in several ways, such as improving film chemistry ${ }^{27,28}$, incorporating additives and/or reinforcements $^{29,30}$ and preforming thermal pre-treatment ${ }^{31-33}$, which will be expanded in further work.

\section{Conclusions}

The fabricated Nafion films have been developed into reference electrodes for use in aqueous solutions. Four redox couples, namely $\mathrm{MV}^{2+} / \mathrm{MV}^{+}, \mathrm{Ru}(\mathrm{bpy})_{3}{ }^{2+} / \mathrm{Ru}(\mathrm{bpy})_{3}{ }^{3+}, \mathrm{Fc} / \mathrm{Fc}^{+}$and $\mathrm{PVFc}_{\mathrm{PVFc}}{ }^{+}$Nafion film reference electrodes were fabricated and optimised and they exhibit good stability over 10 days, in particular the $\mathrm{Fc} / \mathrm{Fc}^{+}$Nafion films demonstrate the best performance. This is attributed in part to the strong binding of the cationic species within the Nafion films and the water insolubility of $\mathrm{Fc}$ and $\mathrm{PVFc} . \mathrm{MV}^{2+} / \mathrm{MV}^{+}, \mathrm{Ru}(\mathrm{bpy})_{3}{ }^{2+} / \mathrm{Ru}(\mathrm{bpy})_{3}{ }^{3+}$ and $\mathrm{PVFc} / \mathrm{PVFc}^{+}$Nafion films have a small initial potential drift $(<30 \mathrm{mV})$ after first a few minutes fabrication before the potential fully stabilization. This drift likely results from the inhomogeneous distribution of generated product within the film during the fabrication process and can be fully eliminated by careful dopant couple selection. Comparing with conventional reference electrodes such as the $\mathrm{Ag} / \mathrm{AgCl}$ electrode, or the saturated calomel electrode (SCE), the proposed Nafion film reference electrode has several advantages: the film electrode is a solid-state liquid-free reference electrode, and no contamination of the test solution. The type of electrode is easy and simple to fabricate, and the film can be dropcasted on different substrates, such as cheap graphite rods. The substrate can be very small hence the electrode could be miniaturized for application in analytical devices at nanoscales, such as scanning electrochemical microscopy (SECM) and scanning probe microscopy (SPM). 


\section{Associated Content}

Supporting Information Available: The following files are available free of charge.

Supporting Infomration: Additional figures; Stability of other Nafion film electrodes under optimized conditions; Estimation of the Nafion film thickness; Experimental details for the fabrication of other Nafion film electrodes; Estimation of the relative amount of dopant redox species in Nafion film reference electrodes; Fabrication of the Nafion particle reference electrodes.

\section{Corresponding Author}

*E-mail: richard.compton@chem.ox.ac.uk. Telephone: +44(0) 1865275957

\section{Notes}

The authors declare no competing financial interests.

\section{Acknowledgements}

LC would like to acknowledge the China Oxford Scholarship Fund and the Great BritainChina Educational Trust for financial support to his DPhil. 


\section{References}

1. Thackray, A.; Myers, M., Arnold O. Beckman: One hundred years of excellence. Chemical Heritage Foundation: 2000.

2. Beckman, A. O.; Fracker, H. E., Apparatus for testing acidity. U.S. Patent 2058761 1936.

3. Jonte, J. H.; Martin Jr, D. S., The Solubility of Silver Chloride and the Formation of Complexes in Chloride Solution1. Journal of the American Chemical Society 1952, 74 (8), 2052-2054.

4. Seward, T. M., The stability of chloride complexes of silver in hydrothermal solutions up to 350 C. Geochimica et Cosmochimica Acta 1976, 40 (11), 1329-1341.

5. Yang, H.; Li, X.; Batchelor-McAuley, C.; Sokolov, S. V.; Kätelhön, E.; Compton, R. G., Immobilised Electrocatalysts: Nafion Particles Doped with Ruthenium(II) Tris(2,2'bipyridyl). 2017, 23 (69), 17605-17611.

6. Chen, L.; Lin, C.; Compton, R. G., Single entity electrocatalysis: oxygen reduction mediated via methyl viologen doped Nafion nanoparticles. Physical Chemistry Chemical Physics 2018, 20 (23), 15795-15806.

7. Chen, L.; Lin, C.; Compton, R. G., Electrochemical characterisation and comparison of transport in Nafion films and particles. Physical Chemistry Chemical Physics 2019, 21 (2), 607-616.

8. Rubinstein, I.; Bard, A. J., Polymer films on electrodes. 4. Nafion-coated electrodes and electrogenerated chemiluminescence of surface-attached tris(2,2'bipyridine)ruthenium(2+). Journal of the American Chemical Society 1980, 102 (21), 66416642.

9. Buttry, D. A.; Anson, F. C., Effects of electron exchange and single-file diffusion on charge propagation in Nafion films containing redox couples. Journal of the American Chemical Society 1983, 105 (4), 685-689.

10. Sheppard, S.-A.; A. Campbell, S.; R. Smith, J.; W. Lloyd, G.; C. Walsh, F.; R. Ralph, T., Electrochemical and microscopic characterisation of platinum-coated perfluorosulfonic acid (Nafion 117) materials $\dagger$. Analyst 1998, 123 (10), 1923-1929.

11. Momma, T.; Kakuda, S.; Yarimizu, H.; Osaka, T., Electrochemical redox properties of polypyrrole/Nafion composite film in a solid polymer electrolyte battery. Journal of the Electrochemical Society 1995, 142 (6), 1766-1769.

12. Jaworska, E.; Naitana, M. L.; Stelmach, E.; Pomarico, G.; Wojciechowski, M.; Bulska, E.; Maksymiuk, K.; Paolesse, R.; Michalska, A., Introducing Cobalt(II) Porphyrin/Cobalt(III) Corrole Containing Transducers for Improved Potential Reproducibility and Performance of All-Solid-State Ion-Selective Electrodes. Analytical Chemistry 2017, 89 (13), 7107-7114.

13. Zhen, X. V.; Rousseau, C. R.; Bühlmann, P., Redox Buffer Capacity of Ion-Selective Electrode Solid Contacts Doped with Organometallic Complexes. Analytical Chemistry 2018, 90 (18), 11000-11007.

14. Grygolowicz-Pawlak, E.; Crespo, G. A.; Ghahraman Afshar, M.; Mistlberger, G.; Bakker, E., Potentiometric Sensors with Ion-Exchange Donnan Exclusion Membranes. Analytical Chemistry 2013, 85 (13), 6208-6212.

15. Krtil, P.; Trojánek, A.; Samec, Z., Kinetics of Water Sorption in NafionThin Films Quartz Crystal Microbalance Study. The Journal of Physical Chemistry B 2001, 105 (33), 7979-7983.

16. Wang, Y.; Limon-Petersen, J. G.; Compton, R. G., Measurement of the diffusion coefficients of $[\mathrm{Ru}(\mathrm{NH} 3) 6] 3+$ and $[\mathrm{Ru}(\mathrm{NH} 3) 6] 2+$ in aqueous solution using microelectrode 
double potential step chronoamperometry. Journal of Electroanalytical Chemistry 2011, 652 (1), 13-17.

17. Borup, R.; Meyers, J.; Pivovar, B.; Kim, Y. S.; Mukundan, R.; Garland, N.; Myers, D.; Wilson, M.; Garzon, F.; Wood, D.; Zelenay, P.; More, K.; Stroh, K.; Zawodzinski, T.; Boncella, J.; McGrath, J. E.; Inaba, M.; Miyatake, K.; Hori, M.; Ota, K.; Ogumi, Z.; Miyata, S.; Nishikata, A.; Siroma, Z.; Uchimoto, Y.; Yasuda, K.; Kimijima, K.-i.; Iwashita, N., Scientific Aspects of Polymer Electrolyte Fuel Cell Durability and Degradation. Chemical Reviews 2007, 107 (10), 3904-3951.

18. Rodgers, M. P.; Bonville, L. J.; Kunz, H. R.; Slattery, D. K.; Fenton, J. M., Fuel Cell Perfluorinated Sulfonic Acid Membrane Degradation Correlating Accelerated Stress Testing and Lifetime. Chemical Reviews 2012, 112 (11), 6075-6103.

19. Mauritz, K. A.; Moore, R. B., State of Understanding of Nafion. Chemical Reviews 2004, 104 (10), 4535-4586.

20. Kim, Y. S.; Lee, K.-S., Fuel Cell Membrane Characterizations. Polymer Reviews 2015, 55 (2), 330-370.

21. Kusoglu, A.; Weber, A. Z., New Insights into Perfluorinated Sulfonic-Acid Ionomers. Chemical Reviews 2017, 117 (3), 987-1104.

22. Liu, W.; Suzuki, T.; Mao, H.; Schmiedel, T., Development of thin, reinforced PEMFC membranes through understanding of structure-property-performance relationships. ECS Transactions 2013, 50 (2), 51-64.

23. Rubinstein, I.; Bard, A. J., Polymer films on electrodes. 5. Electrochemistry and chemiluminescence at Nafion-coated electrodes. Journal of the American Chemical Society 1981, 103 (17), 5007-5013.

24. Gebel, G.; Diat, O., Neutron and X-ray Scattering: Suitable Tools for Studying Ionomer Membranes. Fuel Cells 2005, 5 (2), 261-276.

25. Hickner, M. A.; Pivovar, B. S., The Chemical and Structural Nature of Proton Exchange Membrane Fuel Cell Properties. Fuel Cells 2005, 5 (2), 213-229.

26. Duncan, A. J.; Leo, D. J.; Long, T. E., Beyond Nafion: Charged Macromolecules Tailored for Performance as Ionic Polymer Transducers. Macromolecules 2008, 41 (21), 7765-7775.

27. Kim, Y. S.; Welch, C. F.; Hjelm, R. P.; Mack, N. H.; Labouriau, A.; Orler, E. B., Origin of Toughness in Dispersion-Cast Nafion Membranes. Macromolecules 2015, 48 (7), 2161-2172.

28. Moore, R. B.; Martin, C. R., Chemical and morphological properties of solution-cast perfluorosulfonate ionomers. Macromolecules 1988, 21 (5), 1334-1339.

29. D'Urso, C.; Oldani, C.; Baglio, V.; Merlo, L.; Aricò, A. S., Towards fuel cell membranes with improved lifetime: Aquivion ${ }^{\circledR}$ Perfluorosulfonic Acid membranes containing immobilized radical scavengers. Journal of Power Sources 2014, 272, 753-758.

30. Laberty-Robert, C.; Vallé, K.; Pereira, F.; Sanchez, C., Design and properties of functional hybrid organic-inorganic membranes for fuel cells. Chemical Society Reviews 2011, 40 (2), 961-1005.

31. Gebel, G.; Aldebert, P.; Pineri, M., Structure and related properties of solution-cast perfluorosulfonated ionomer films. Macromolecules 1987, 20 (6), 1425-1428.

32. Alberti, G.; Narducci, R., Evolution of Permanent Deformations (or Memory) in Nafion 117 Membranes with Changes in Temperature, Relative Humidity and Time, and Its Importance in the Development of Medium Temperature PEMFCs. Fuel Cells 2009, 9 (4), 410-420.

33. Collette, F. M.; Lorentz, C.; Gebel, G.; Thominette, F., Hygrothermal aging of Nafion®. Journal of Membrane Science 2009, 330 (1), 21-29. 
For TOC only

$\mathrm{FC} / \mathrm{FC}^{+} \mathrm{PF}_{6}{ }^{-}$in Nafion film

Carbon substrate 